\title{
Review Article \\ Role of Exosomal Noncoding RNAs in Lung Carcinogenesis
}

\author{
Tao Sun, ${ }^{1}$ Bill Kalionis, ${ }^{2}$ Guoying Lv, ${ }^{3}$ Shijin Xia, ${ }^{1}$ and Wen Gao ${ }^{4}$ \\ ${ }^{1}$ Shanghai Institute of Geriatrics, Huadong Hospital, Fudan University, Shanghai 200040, China \\ ${ }^{2}$ Department of Perinatal Medicine, Pregnancy Research Centre and University of Melbourne Department of Obstetrics \\ and Gynaecology, Royal Women's Hospital, Parkville, VIC 3052, Australia \\ ${ }^{3}$ Emergency Department of Wuhan Hospital of Traditional Chinese Medicine, Wuhan 430010, China \\ ${ }^{4}$ Department of Thoracic Surgery, Huadong Hospital, Fudan University, Shanghai 200040, China
}

Correspondence should be addressed to Shijin Xia; xiashijinhd@163.com and Wen Gao; gaowen5921@163.com

Received 17 April 2015; Revised 5 July 2015; Accepted 16 July 2015

Academic Editor: Denis Corbeil

Copyright (C) 2015 Tao Sun et al. This is an open access article distributed under the Creative Commons Attribution License, which permits unrestricted use, distribution, and reproduction in any medium, provided the original work is properly cited.

\begin{abstract}
Lung cancer is the major cause of cancer death worldwide. Novel, recently discovered classes of noncoding RNAs (ncRNAs) have diverse functional and regulatory activities and increasing evidence suggests crucial roles for deregulated ncRNAs in the onset and progression of cancer, including lung cancer. Exosomes are small extracellular membrane vesicles of endocytic origin that are released by many cells and are found in most body fluids. Tumor-derived exosomes mediate tumorigenesis by facilitating tumor growth and metastasis. MicroRNAs (miRNAs) are a subclass of ncRNAs that are present in exosomes. miRNAs are taken up by neighboring or distant cells and modulate various functions of recipient cells. Here, we review exosome-derived ncRNAs with a focus on miRNAs and their role in lung cancer biology.
\end{abstract}

\section{Introduction}

Lung cancer is one of the most lethal human cancers worldwide. Nonsmall cell lung cancers (NSCLC) are the majority of lung cancers (80\%) while the remaining are small cell lung cancers (SCLC) [1]. Despite recent advances in lung cancer research and the use of novel therapeutic agents for NSCLC, outcomes remain dismal with a 5-year survival rate of about $15 \%$ [1]. A deeper understanding of the molecular mechanisms underlying NSCLC development and progression is needed.

ncRNAs are a novel class of RNA molecules that perform many basic regulatory functions in eukaryotes and these include regulating normal cell growth and apoptosis but they also play roles in abnormal cell functions associated with cancer progression and metastasis [2,3]. However, the functional role of ncRNAs in NSCLC is not well understood. ncRNAs are a large class of molecules that can be divided into two groups based on their transcript lengths: small ncRNAs ( $<200 \mathrm{bp}$ ), such as transfer RNAs (tRNAs), ribosomal RNAs (rRNAs), small nucleolar RNAs (snoRNAs), microRNAs (miRNAs), small interfering RNAs (siRNA), PIWI-interacting RNAs (piRNA), antisense RNAs, and promoter-associated RNAs (PARs) and long ncRNAs (lncRNAs, $>200$ bp) [4].

Cell-cell communication can occur by several means, including chemical receptor-mediated events, direct cell-cell contact and cell-cell synapses. Extracellular vesicles (EVs), which include exosomes and microvesicles, are mediators of cell-cell communication and are novel biomarkers for disease. Increasing evidence implicates cell-to-cell communication, which can be mediated by delivery of miRNAs after transfer through exosomes, in physiological and pathological processes. Exosomes are subcellular vesicles $(30-120 \mathrm{~nm}$ in diameter) present in biological fluids. Different miRNAs including let-7, miR-1, miR-15, miR-16, miR-181, and miR375 , which seem to be specifically packaged exclusively into exosomes [5], have sparked intense investigations into the composition and function of exosomes. miRNAs are small ncRNA gene products discovered in diverse organisms that are thought to regulate target gene expression [6]. A potential role for miRNAs in carcinogenesis comes from their ability to inhibit the translation of tumor suppressor genes and 
oncogenes. Many human cancers display unique miRNA expression signatures. miRNAs can be secreted via extracellular vesicles (EVs) and by protein-miRNA complexes. Current studies show that miRNAs are present in extracellular spaces, packaged into various membrane-bound vesicles. The protein-miRNA content of EVs can be transferred to recipient cells and deliver biological information that plays an important role in cancer metastasis and prognosis.

Exosomal miRNAs are also body fluid miRNAs but they differ from free miRNAs circulating in the body fluid because they are encapsulated in exosomes derived from the multivesicular body (MVB) sorting pathway [7]. Exosomes are distributed in various body fluids and are taken up by neighboring or distant cells. In doing so, miRNAs are delivered to the recipient cell and then they alter cell functions. Ratajczak et al. showed RNA contained within exosomes was responsible for the horizontal transfer of genetic information between cells [8]. Ribonuclease pretreatment inhibited the functional effects of exosomes, which provided convincing evidence of RNA involvement. Following translocation from the nucleus to the cytoplasm, RNA molecules bind to membranous organelles or vesicles and are transported to intracellular sites, which may account for RNA populations associating with exosomes. Valadi et al. showed that exosomes contain a subset of both cellular mRNA and miRNA, which could be transferred to recipient cells [5].

Many studies show that miRNAs are differentially enriched in normal exosomes compared with exosomes from pathological conditions such as tumors. Exosome-containing miRNAs are implicated in cancer pathogenesis [9]. For example, microarray analysis revealed selective enrichment of let-7 miRNA family in exosomes derived from highly metastatic gastric cancer cells, when compared with lowly metastatic gastric cells [10]. Members of the let-7 miRNA family have tumour suppressor activity that targets oncogenes such as RAS and HMGA2. Ohshima et al. [10] proposed a mechanism where highly invasive tumour cells release let-7 miRNAs through exosomes into the extracellular milieu, to maintain their tumourigenic phenotype.

Cancer cell communication is an important and complex process, which is achieved through diverse mechanisms and allows tumor cells to mold and influence their environment. Recent evidence shows that cells communicate via the release and delivery of miRNAs packed into tumor-released (TR) exosomes. Some miRNAs are either over- or underexpressed in particular cancer types. Patterns of miRNAs are unique to individual tissue types and differ between cancer and normal samples $[11,12]$. Current data support miRNAs as potential biomarkers for NSCLC [13-17]. Measurement of levels of multiple miRNAs can more precisely gauge prognosis and accurately predict survival in lung cancer [18].

\section{The Release Mechanism of Circulating miRNAs}

The biological mechanisms that culminate in the release of circulating miRNAs remain unclear. Possible mechanisms for miRNA release include (1) active secretion of miRNAs as vesicle-containing miRNAs and (2) energy-free passive leakage of cellular miRNAs from disrupted cells. The latter mechanism is only a minor contributor to the process of circulating miRNA generation and occurs predominantly under pathological circumstances such as tissue damage, cell apoptosis, tumor metastatic process, or chronic inflammation [19, 20]. Circulating miRNAs are packaged into various membrane-bound vesicles including exosomes and microvesicles [5], whereas vesicle-free miRNAs are associated with protein or high-density lipoprotein complexes [21]. Only EV-derived miRNAs function in cell-cell communication, and they play roles in various biological processes including immune system regulation, inflammation, and tumor development $[22,23]$. EV-derived miRNAs control many aspects of human physiological status and are therefore potentially better disease biomarkers than other circulating miRNAs.

Unfortunately, the release mechanism of circulating miRNAs by tumors is not well established. Rabinowits et al. evaluated the exosomal miRNA circulating levels of patients with lung adenocarcinoma and compared them with those of patients without lung cancer, showing that the miRNA signatures of exosomes parallel those of the miRNA expression profiles of the originating tumor cells. This indicates that the content of tumor cell-derived exosomes is correlated with the miRNA levels in primary tumor [24]. Fabbri et al. provided evidence that, in immune cells, tumor-secreted miR-21 and miR-29a act as ligands that bind receptors of the toll-like receptor (TLR) family, specifically human TLR8, and murine TLR7. Tumor growth and metastasis would be a consequence miRNA binding to TLR that mediates a prometastatic inflammatory response [9].

\section{Potential Modes for Sorting of miRNAs into Exosomes}

Current research describes four possible modes for sorting of the specific loading of miRNA species into exosomes, although the underlying mechanisms are unclear (Figure 1).

The first mode of sorting involves the miRNA-induced silencing complex- (miRISC-) related pathway. Mature miRNAs can interact with assembly proteins to form a complex called miRISC, which includes miRNA, miRNA-repressible mRNA, GW182 protein, and miRNA effector protein argonaute 2 (AGO2). Multivesicular bodies (MVBs, also called late endosomes) are derived from early endosomes. MVBs either release exosomes into the extracellular space upon fusion with plasma membrane or fuse with lysosomes and degrade their content. GW-bodies are distinct foci within the eukaryotic cell cytoplasm that participate in various types of mRNA decay and miRNA-induced mRNA silencing. Gibbings et al. showed GW-bodies appear to contain most of the miRISC complex components (including GW182 protein and AGO2), colocalise with MVBs, and may be sites where miRISCs accumulate and act. They also showed that exosome-like vesicles produced by MVBs were enriched in GW182 protein but not AGO2. Furthermore, blocking the formation of MVB by reducing endosomal sorting complex, required for transport (ESCRT) components, 


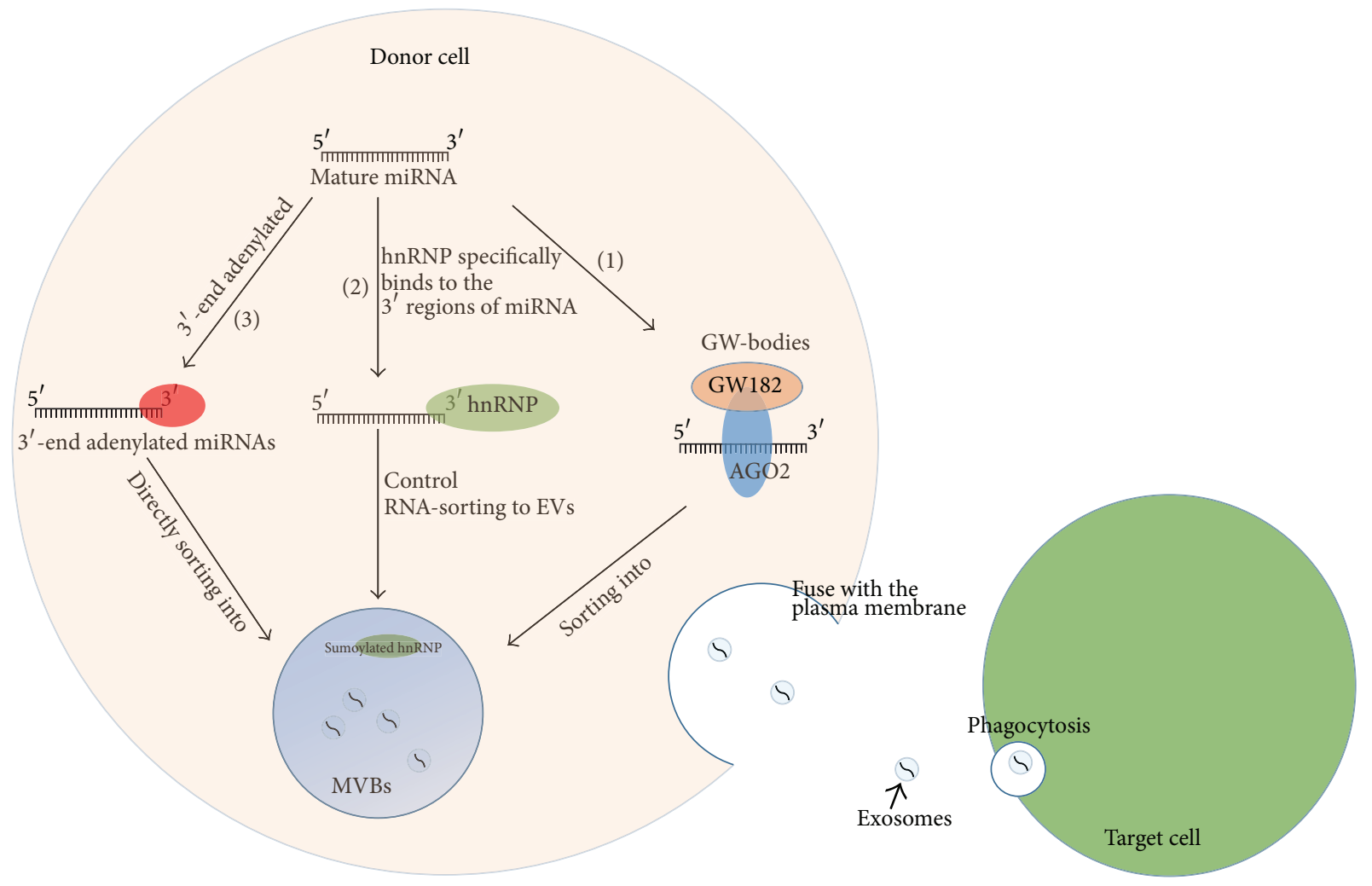

FIGURE 1: Potential modes for sorting of miRNAs into exosomes: (1) Mature miRNAs can interact with assembly proteins to form a complex called miRISC, which includes target miRNA, miRNA-repressible mRNA, GW182 protein, and miRNA effector protein argonaute 2 (AGO2, which was initially identified as membrane associated). Active miRISCs are recruited into GW-bodies that are physically associated with MVBs and this may represent a method of loading miRNAs into exosomes. (2) The protein hnRNP specifically binds to the $3^{\prime}$ regions of miRNA sequences and controls their loading into exosomes. (3) $3^{\prime}$-end adenylated miRNAs directly sort into EVs. miRNAs release as exosomes and uptake by recipient cell: (a) MVBs are released by exocytosis and fuse with the plasma membrane leading to the release of exosomes. (b) EVs uptake by recipient cells through phagocytosis.

reduced miRNA-mediated gene silencing and resulted in excess accumulation of GW182 protein, while preventing the fusion of MVBs with lysosomes stimulated RISC activity. These data are consistent with the idea that active miRISCs with target mRNAs are recruited into GW-bodies that are physically associated with MVBs and this may represent a method of loading miRNAs into exosomes [25]. The second mode involves a miRNA motif and the sumoylated heterogeneous nuclear ribonucleoproteins- (hnRNPs-) dependent pathway. The protein hnRNPA2B1 specifically binds exosomal miRNAs through the recognition of these motifs in the $3^{\prime}$ regions of miRNA sequences and controls their loading into exosomes. In addition, hnRNPA2B1 in exosomes is preferentially sumoylated, and this sumoylation is important for the loading of exosomal miRNAs into exosomes. The loading of miRNAs into exosomes can be modulated by mutagenesis of the identified motifs or changes in hnRNPA2B1 expression levels [26]. Another two hnRNP family proteins, hnRNPAl and hnRNPC, could also bind to exosomal miRNAs, suggesting that they might also be candidates for miRNA sorting [27]. The third mode relies on a pathway dependent on the $3^{\prime}$ ends of the miRNA. $3^{\prime}$-end adenylated miRNAs are relatively enriched in cells, whereas $3^{\prime}$-end uridylated isoforms appear overrepresented in exosomes derived from B cells or urine. Collectively, it suggests that posttranscriptional modifications, notably $3^{\prime}$-end adenylation and uridylation, exert opposing effects that may contribute to direct ncRNA sorting into EVs [27]. Therefore, two sorting modes show that the $3^{\prime}$ regions or the $3^{\prime}$ ends of the miRNA sequence contain as yet unidentified critical sorting signal(s). The last mode is mediated by the neural sphingomyelinase 2- (nSMase2-) dependent pathway. Kosaka et al. demonstrate that nSMase2 regulates exosomal miRNA secretion and promotes angiogenesis within the tumor microenvironment as well as metastasis. nSMase2 is the initial molecule associated with miRNA secretion into exosomes. Overexpressed nSMase2 increased the number of exosomal miRNAs whereas inhibition of nSMase2 expression had the converse effect [28].

There are two ways for microvesicles secreting from donor cells: (1) microvesicles are directly shed from the cell membrane; and (2) MVBs which are released by exocytosis fuse with the plasma membrane and release the intraluminal endosomal vesicles into the extracellular space to become exosomes [29]. The miRNAs in cell-released exosomes can circulate with the associated vehicles to reach neighboring 
cells and distant cells. EVs, which interact with the functionally active receptors (CCR5, EGFRvIII, or MET) or ligands of target cells, may induce changes in the cell phenotype, eventually leading to triggering intracellular signaling pathways [30]. EVs uptake by recipient cells seems to occur through phagocytosis [31]. After being delivered into target cells, exosomal miRNAs play functional roles (Figure 1).

\section{The ncRNAs Related to Lung Cancer}

Great progress in the last decade has increased our understanding of the role miRNAs play in lung cancer. Several miRNAs that display different patterns in lung cancer compared to normal tissues were identified. Aberrant miRNA levels were detected in lung cancer tumor tissues but also in body fluids and extracellular organelles, such as exosomes. These combined studies gave weight to the notion that miRNAs are promising biomarkers for improved diagnosis and prediction, and they are potential targets for therapeutics to treat lung cancer.

Cazzoli et al. screened 742 miRNAs in circulating exosomes and identified four miRNAs (miR-378a, miR-379, miR$139-5 p$, and miR-200b-5p) as screening markers to segregate lung adenocarcinoma and carcinoma patients, from healthy former smokers. They also identified six miRNAs (miR-15la5p, miR-30a-3p, miR-200b-5p, miR-629, miR-100, and miR$154-3 p)$ that segregated lung adenocarcinoma patients and lung granuloma patients [32].

In 2004, Takamizawa et al. [33] identified the first miRNA family, let-7, which was associated with the tumorigenesis of lung cancer. They found that introduction of let-7a and let-7f isoforms into a lung adenocarcinoma cell line with low baseline levels of let-7 expression (A549), inhibited the growth of A549 cells. In a clinical setting, reduced let-7 levels were associated with shorter patient survival after diagnosis. Many targets of let-7 are now known, including the RAS family [34], HMGA2 [34-36], c-Myc [37, 38], CDC25A, CDK6, and Cyclin D2 [39]. These target genes helped to reveal the mechanisms by which let-7 family members exert their function in tumorigenesis. Many miRNAs are oncogenes or tumor suppressor genes and these include miR-17-92 [16, 40], miR-218 [41], miR-21 [42], and miR-34 family members (miR$34 \mathrm{a}$ and $\mathrm{miR}-34 \mathrm{~b} / \mathrm{c}$ ) [43-47]. miRNAs play pivotal roles in lung tumorigenesis and are also involved in tumor metastasis. Several miRNAs including miR-17-92 [48-51], the miR-200 family of miRNAs (miR-200a, miR-200b, miR-200c, miR141, and miR-429) [52], miR-125a-3p/5p [53], miR-21 [54], and the miR-106b-25 cluster (miR-106b and miR-93) [55] are implicated in metastatic lung cancer. Many other miRNAs and their potential mechanism(s) of action are shown in Table 1.

Besides miRNAs, long ncRNAs (lncRNAs) with tumourpromoting and tumour-suppressing functions in lung cancer have also been identified [56]. MALAT1 is lncRNA present at high levels, which is upregulated during metastasis of early-stage NSCLC and is a powerful predictor of metastatic relapse in patients with NSCLC. SCAL1 is lncRNA that shows increased levels as part of the oxidative stress response of airway epithelial cells to cigarette smoke. SCAL1 is also overexpressed in a range of lung cancer cell lines, which may indicate a novel mechanism of smoke-induced malignant transformation. Yang et al. characterized the function of lncRNA PVT1 in NSCLC development and progression [57]. PVT1 levels were increased in NSCLC tissues and lung cancer cell lines when compared with matching nearby normal tissues and the normal human bronchial epithelial cell line $16 \mathrm{HBE}$, respectively. They also found PVT1 levels correlated positively with histological grade and lymph node metastasis, but there was no correlation with age, gender, and tumor size in patients with NSCLC. High levels of PVT1 correlated with lower overall survival rates and were an independent prognostic factor in patients with NSCLC. These results provided evidence of a potentially important role of PVT1 in tumorigenesis and in the progression of NSCLC. Other lncRNAs and their potential mechanism(s) of action are shown in Table 2.

\section{Potential Mechanism of Some Exosomal miRNAs}

Silva et al. showed levels of exosomal let-7f and/or miR-30e$3 p$ in NSCLC patients could distinguish between patients with resectable and nonresectable tumors [58]. Rabinowits et al. assessed patients with and without lung adenocarcinoma for their levels of circulating tumor exosomes and exosomal small RNA as well as specific exosomal miRNAs. Subsequently, these levels were correlated with disease stages as defined by the American Joint Committee on Cancer (AJCC). These studies were used to validate markers for diagnosis and prognosis in patients for lung adenocarcinoma. The levels of 12 exosomal miRNAs (miR-17-3p, miR-21, miR-106a, miR146, miR-155, miR-191, miR-192, miR-203, miR-205, miR-210, miR-212, and miR-214) were significantly different between patients and controls [24]. The potential mechanism(s) of those 12 exosomal miRNAs are shown in Table 1.

The analysis of specific miRNAs in exosomes showed enrichment of miRNAs in samples from patients with NSCLC both in plasma and in bronchoalveolar lavage. This finding, together with the higher proportion of exosomes detected in the plasma of NSCLC patients, supports the idea that a proliferative advantage accrues to tumors that release exosomes into plasma [59].

let-7 was the first miRNA shown to be dysregulated in human lung cancer [33]. Decreased levels of let-7 in the sputum of patients with chronic obstructive pulmonary disease (COPD) fueled speculation that chronic airway inflammation, combined with the loss of a major tumour suppressor, may contribute to the increased risk of patients with COPD developing lung cancer. Yu et al. identified a five-miRNA signature that can predict survival in patients with lung cancer, of which hsa-miR-221 and hsa-let-7a were protective, while hsa-miR-137, hsa-miR-372, and hsa-miR-182* were nonprotective [18]. In patients with lung cancer, the total levels of exosomes and their let-7 miRNAs increased compared to controls. Ohshima et al. performed extensive miRNA analysis in three cellular fractions including cells, 
TABLE 1: The potential mechanisms and target genes of miRNAs in lung cancer.

\begin{tabular}{|c|c|c|c|}
\hline Onco-miRNA & Potential mechanisms & Target genes & Reference \\
\hline miR-21 & $\begin{array}{l}\text { Overexpression of miR-21 enhances tumorigenesis and inhibits } \\
\text { apoptosis through inhibition of negative regulators of the } \\
\text { Ras/MEK/ERK pathway and inhibition of apoptosis }\end{array}$ & $\begin{array}{l}\text { PTEN, SPRY1, SPRY2, BTG2, } \\
\text { PDCD4, APAF1, FasL, and RHOB }\end{array}$ & {$[42]$} \\
\hline miR-212 & $\begin{array}{l}\text { Exert an antiapoptotic effect through direct repression of synaptic } \\
\text { acetylcholinesterase expression in NSCLC }\end{array}$ & $\mathrm{AChE}$ & {$[60]$} \\
\hline $\begin{array}{l}\text { miR-17-92 } \\
\text { cluster }\end{array}$ & $\begin{array}{l}\text { Enhances cell proliferation, inhibits apoptosis, and protects against } \\
\text { DNA damage }\end{array}$ & $\begin{array}{l}\text { p21, CTGF, Tsp1, PTEN, Bim, and } \\
\text { HIF- } 1 \alpha\end{array}$ & {$[16,61]$} \\
\hline miR-221-222 & $\begin{array}{l}\text { Activates the PI3K/Akt } \\
\text { pathway and metallopeptidases }\end{array}$ & $\begin{array}{l}\text { Kit, p27 kip1, PTEN/TIMP3, } \\
\text { PUMA, and TRAIL }\end{array}$ & {$[62]$} \\
\hline $\begin{array}{l}\operatorname{miR}-93 \\
\operatorname{miR}-98 \text {, and } \\
\operatorname{miR}-197\end{array}$ & Inhibits tumor suppressor gene FUS1 expression & FUS1 & {$[63]$} \\
\hline miR-375 & $\begin{array}{l}\text { miR-375 upregulation and correlates with ASCL1 in the cell lines } \\
\text { generated from mouse SCLC-like tumors }\end{array}$ & Not determined & {$[64]$} \\
\hline $\begin{array}{l}\text { miR-17-5p and } \\
\text { miR-20a }\end{array}$ & $\begin{array}{l}\text { miRNA inhibition reduces cell growth } \\
\text { miRNA inhibition induces apoptosis and increases the proportions of } \\
\text { sub-G1 populations }\end{array}$ & E2F1 & {$[65]$} \\
\hline miR-328 & $\begin{array}{l}\text { Associated with cell migration and NSCLC brain metastases by } \\
\text { controlling the VEGF/IL1 signaling pathway }\end{array}$ & $\begin{array}{l}\text { PRKCA, VEGF-D, NOTCH1, IL1- } \alpha \text {, } \\
\text { IL1- } \beta \text {, and PLC- } \gamma\end{array}$ & {$[66]$} \\
\hline miR-106 & Upregulated in lung cancer & $\mathrm{RB}$ & {$[67]$} \\
\hline miR-155 & $\begin{array}{l}\text { Promotes cell proliferation through the repression of SOCS1. } \\
\text { Downregulates several tumor suppressors such as PTEN, PDC4, and } \\
\text { SHIP1, leading to the activation of the Akt pathway } \\
\text { Plays a role in cell invasion by targeting RhoA }\end{array}$ & $\begin{array}{l}\text { CASP3, TP53BP1, SOCS1, PTEN, } \\
\text { PDC4, and SHIP1 }\end{array}$ & {$[68-70]$} \\
\hline $\begin{array}{l}\text { Tumor } \\
\text { suppressor } \\
\text { miRNA }\end{array}$ & Potential mechanisms & Target genes & Reference \\
\hline let-7 family & $\begin{array}{l}\text { Suppress cell proliferation by negatively regulating pathways } \\
\text { promoting the G1 to } S \text { transition }\end{array}$ & $\begin{array}{l}\text { KRAS, CDC25a, CDK6, c-MYC, } \\
\text { CCND1, and BCL-2 }\end{array}$ & {$[39,71]$} \\
\hline miR-126 & $\begin{array}{l}\text { Inhibits cell proliferation by arresting the cells in the G1 phase by } \\
\text { targeting VEGF }\end{array}$ & VEGF, CRK, and SLC7A5, & {$[49,72]$} \\
\hline miR-26a & $\begin{array}{l}\text { Inhibits cell proliferation, blocks G1/S phase transition, induces } \\
\text { apoptosis, and inhibits cell metastasis and invasion in vitro }\end{array}$ & $\mathrm{EZH} 2$ & {$[73]$} \\
\hline miR-7 & $\begin{array}{l}\text { Involved in miR-7-mediated growth suppression and apoptosis } \\
\text { Inhibits cancer cell migration }\end{array}$ & BCL-2 & {$[74]$} \\
\hline miR-335 & Reduces cell migration, invasion, proliferation, and metastasis & BCL-W and SP1 & {$[75]$} \\
\hline miR-145 & $\begin{array}{l}\text { Inhibits cell growth, proliferation, and migration of lung cancer cells } \\
\text { and induces cell cycle arrest in G1 by targeting CDK4 }\end{array}$ & $\begin{array}{l}\text { EGFR, NUDT1, CDK } 4, \mathrm{c}-\mathrm{Myc} \text {, and } \\
\text { OCT4 }\end{array}$ & {$[76-78]$} \\
\hline $\operatorname{miR}-413$ & Inhibits cell proliferation and enhances apoptosis & $\mathrm{PKC} \varepsilon$ & {$[79]$} \\
\hline miR-192 & $\begin{array}{l}\text { Inhibits cell proliferation and induces cell apoptosis in lung cancer } \\
\text { cells } \\
\text { Arrests cells in G1 phase }\end{array}$ & $\mathrm{RB} 1$ & {$[80]$} \\
\hline miR-449 cluster & $\begin{array}{l}\text { Induces apoptosis targeting Bcl-2, n-MYC, and HDAC1 and } \\
\text { upregulates p53 through the repression of deacetylase gene SIRT1 } \\
\text { Inhibits cell migration and invasion by suppression of AXL and } \\
\text { SNAIL-1 }\end{array}$ & $\begin{array}{l}\text { CDK4, CDK6, c-MYC, CCND1, } \\
\text { CCNE2, CDC25A, MET, and E2F }\end{array}$ & {$[81-83]$} \\
\hline miR-206 & $\begin{array}{l}\text { Overexpression of miR-206 inhibits migration and invasion of lung } \\
\text { cancer cells }\end{array}$ & Not determined & {$[84]$} \\
\hline miR-146a & $\begin{array}{l}\text { Inhibits cell growth and induces cell apoptosis } \\
\text { Suppresses motility } \\
\text { Enhances cell proliferation inhibitory effect of TKIs and cetuximab }\end{array}$ & EGFR & {$[85]$} \\
\hline miR-203 & Inhibits cell proliferation and migration of lung cancer & $\mathrm{PKC} \alpha$ & {$[86]$} \\
\hline miR-205 & $\begin{array}{l}\text { Regulates epithelial to mesenchymal transition by targeting ZEB1 and } \\
\text { SIP1 }\end{array}$ & Not determined & [87] \\
\hline $\operatorname{miR}-214$ & $\begin{array}{l}\text { Regulates the acquired resistance to gefitinib via the PTEN/AKT } \\
\text { pathway }\end{array}$ & PTEN & [88] \\
\hline
\end{tabular}


TABLE 2: The potential mechanisms of lncRNAs in lung cancer.

\begin{tabular}{|c|c|c|}
\hline Onco-lncRNA & Potential mechanism & Reference \\
\hline MVIH & $\begin{array}{l}\text { Affects expression of MMP-2/MMP-9 } \\
\text { Proliferation and invasion }\end{array}$ & [89] \\
\hline BC200 & Upregulated in lung cancer & {$[90]$} \\
\hline lncRNA-DQ786227 & Upregulated in lung cancer & {$[91]$} \\
\hline MALAT1 & Affects expression of Bcl-2 and metastasis related genes & {$[92]$} \\
\hline AK126698 & $\begin{array}{l}\text { Decreases NKD and increases the accumulation and nuclear translocation of } \beta \text {-catenin } \\
\text { Antiapoptotic effects and resistance to cisplatin }\end{array}$ & [93] \\
\hline SCAL1 & $\begin{array}{l}\text { Induced by cigarette smoke and NRF2 } \\
\text { Protective against oxidative stress }\end{array}$ & {$[94]$} \\
\hline HOTAIR & $\begin{array}{l}\text { Induced by Col-1 upregulation of cell adhesion-related genes such as ASTN1 and PCDHA1 } \\
\text { Downregulates genes involved in neuronal growth and signal transduction including NTM } \\
\text { and PTK2B } \\
\text { Contributes to the cisplatin resistance through the regulation of p21 expression } \\
\text { Affects proliferation, migration, and invasion }\end{array}$ & [95-97] \\
\hline Tumor suppressor lncRNA & Potential mechanism & Reference \\
\hline BANCR & $\begin{array}{l}\text { A regulator of EMT during NSCLC } \\
\text { Induces apoptosis and inhibits EMT, migration, invasion, and metastasis }\end{array}$ & [98] \\
\hline MEG3 & Inhibits NSCLC cell proliferation and induces apoptosis by affecting p53 expression & {$[99]$} \\
\hline SPRY4-IT1 & $\begin{array}{l}\text { Promotes NSCLC cell proliferation and metastasis via effects on the epithelial-mesenchymal } \\
\text { transition }\end{array}$ & {$[100]$} \\
\hline TUG1 & $\begin{array}{l}\text { Affects cell proliferation in human NSCLC through epigenetically regulating HOXB7 } \\
\text { expression }\end{array}$ & {$[101]$} \\
\hline
\end{tabular}

exosomes, and medium from cultured cells and they found that let-7 miRNA family is rich in all the fractions from the gastric cancer cell line, AZ-P7a. After comparing the levels of let-7 miRNA family members in exosomes derived from AZ$\mathrm{P} 7 \mathrm{a}$ with exosomes from other cancer cell lines, including the lung cancer cell lines (SBC-3, DMS-35, and NCI-H69), they found members of the let-7 miRNA family were abundant in exosomes derived from AZ-P7a but were less abundant in exosomes derived from other cancer cells. These data were consistent with the notion that exosome-mediated release of let-7 miRNAs into the extracellular milieu resulted in a reduced antitumorigenic effect within the cells and consequently oncogenesis and invasiveness of the cells were sustained [10]. Levels of let-7f, miR-20b, and miR-30e-3p in vesicles from the plasma of NSCLC patients were lower than normal controls [58]. The let-7 family members negatively regulate the oncogene RAS [34], suggesting that let-7 acts biologically as a tumor suppressor.

The let-7 miRNA family members are important regulators that control lung cancer oncogene expression by binding to the $3^{\prime}$ untranslated regions $\left(3^{\prime}\right.$-UTR) of their target mRNAs, and lower levels of let-7 miRNA have been found in NSCLC $[34,102]$. let-7 regulates many key cell cycle protooncogenes (KRAS, CDC25a, CDK6, c-MYC, cyclin D, and BCL-2), and in this way let-7 controls cell proliferation by negatively regulating the pathways promoting the G1 to $S$ transition [39]. An interesting feature of the let-7 family is that the $3^{\prime}$-UTR of KRAS (as well as HRAS, NRAS, and various members of the RAS GTPase family) contain multiple let-7 binding sites, and let-7 levels in lung cancer inversely correlate with KRAS expression [103]. Chin et al. described a novel
SNP (Single Nucleotide Polymorphism) in the $3^{\prime}$-UTR of the KRAS gene that influences let-7 binding to its target site. This variant, the let-7 complementary site (LCS6) in the KRAS $3^{\prime}$-UTR, is associated with KRAS gene upregulation and let7 lower levels; however this polymorphism correlates with a modest increase in lung cancer risk [104]. A recent study identified HOXA1 as a new target of the let-7 family. Zhan et al. showed that let-7c represses NSCLC cell proliferation and tumorigenesis by targeting the $3^{\prime}$-UTR of HOXA1 mRNA, which reduced the expression of CCND1, CDC25A, and CDK2 [71]. He et al. showed that let-7a, a member of let-7 family, negatively regulated the expression of NIRF (Np95/ICBP90-like RING finger protein) through NIRF $3^{\prime}$ UTR. Enforced expression of let-7a in A549 lung cancer cells decreased NIRF leading to a coordinated increase in p $21^{\text {WAF1 }}$ [105]. NIRF binds to methyl-CpGs of the promoter region through a SET and RING finger-associated (SRA) domain. This protein constitutes a complex with HDAC1 (histone deacetylase-1) also via its SRA domain, which binds to methylated promoter regions of various tumor suppressor genes, including p $21^{\mathrm{WAF} 1}$ in cancer cells [106]. Recently [107], let-7c levels were observed to be inversely correlated to levels of ITGB3 (integrin b3, also known as CD61) and MAP4K3, a member of the MAP4K family in NSCLC tissues.

Gao et al. identified miRNA profiles in NSCLC and showed that deregulated expression of miR-21, miR-143, and miR-181a correlated with patient prognosis, suggesting that miRNAs are involved in the initiation and progression of this disease [108]. miR-21 is the most common miRNA in the human lung but at elevated levels miR-21 contributes to the symptomatic development of asthma, idiopathic pulmonary 
fibrosis, and non-small-cell lung cancer (NSCLC) through its effects on inflammatory and cancer suppressing genes. miR21 is an antiapoptotic miRNA and is regulated by the EGFR pathway and miR-21 levels correlate with phosphorylated EGFR levels [109]. miR-21 stimulates cell growth and NSCLC cell invasion by targeting PTEN (phosphatase and tensin homolog), which enhances the RAS/MEK/ERK pathway by repressing negative regulators of the pathway (i.e., Spryl, Spry2, Btg2, and Pdcd4) and by repressing the expression of proapoptotic proteins (e.g., Apaf1, FasL, RhoB, and Pdcd4). miR-21 is also upregulated by KRAS in NSCLC, both in vitro and in vivo, through MAPK/AP-1 activation [42, 109111]. Chiba et al. revealed that exosomes derived from the colorectal cancer cell lines contain miR-21, miR-192, and miR221 and can be delivered into lung cancer A549 cells [112].

miR-126 is a tumor suppressor, because of its antioncogenic properties. miR-126 inhibits NSCLC cell line proliferation through EGFL7 [113] and targets the Sdf-1a cytokine, which reduces mesenchymal stem cell and inflammatory monocyte recruitment to primary tumors, thereby inhibiting lung metastasis [114]. Rodríguez et al. showed that tumors may eliminate miR-126 by exosome liberation [59].

\section{Conclusion}

Exosomes, despite their nanosize, can act as key communication facilitators between cells. Gradually, we are revealing the roles of exosomes in interactions between distant cells and the complex roles of exosomes in tumorigenesis and cancer progression. Exosomes secrete a variety of biological molecules, including miRNAs, proteins, and their complexes. The study of exosomal miRNAs offers a new and exciting approach to understanding the molecular mechanisms of lung cancer biology. However, the study of exosomes in lung carcinogenesis is still in its infancy. Unresolved issues include whether other noncoding RNAs such as lncRNAs are present in exosomes and whether lncRNAs are involved in target gene regulation in recipient cells. Much work remains to be carried out before we have a complete understanding of the role of exosomal ncRNAs in lung carcinogenesis.

\section{Conflict of Interests}

The authors declare that there is no conflict of interests.

\section{References}

[1] R. Siegel, D. Naishadham, and A. Jemal, "Cancer statistics, 2013," CA: Cancer Journal for Clinicians, vol. 63, no. 1, pp. 11-30, 2013.

[2] M. Esteller, "Non-coding RNAs in human disease," Nature Reviews Genetics, vol. 12, no. 12, pp. 861-874, 2011.

[3] E. A. Gibb, C. J. Brown, and W. L. Lam, "The functional role of long non-coding RNA in human carcinomas," Molecular Cancer, vol. 10, article 38, 2011.

[4] B. Ricciuti, C. Mecca, L. Crino et al., "Non-coding RNAs in lung cancer," Oncoscience, vol. 1, no. 11, pp. 674-705, 2014.

[5] H. Valadi, K. Ekström, A. Bossios, M. Sjöstrand, J. J. Lee, and J. O. Lötvall, "Exosome-mediated transfer of mRNAs and
microRNAs is a novel mechanism of genetic exchange between cells," Nature Cell Biology, vol. 9, no. 6, pp. 654-659, 2007.

[6] M. Lagos-Quintana, R. Rauhut, W. Lendeckel, and T. Tuschl, "Identification of novel genes coding for small expressed RNAs," Science, vol. 294, no. 5543, pp. 853-858, 2001.

[7] G. Hu, K. M. Drescher, and X.-M. Chen, "Exosomal miRNAs: biological properties and therapeutic potential," Frontiers in Genetics, vol. 3, article 56, 2012.

[8] J. Ratajczak, K. Miekus, M. Kucia et al., "Embryonic stem cellderived microvesicles reprogram hematopoietic progenitors: Evidence for horizontal transfer of mRNA and protein delivery," Leukemia, vol. 20, no. 5, pp. 847-856, 2006.

[9] M. Fabbri, A. Paone, F. Calore et al., "MicroRNAs bind to Tolllike receptors to induce prometastatic inflammatory response," Proceedings of the National Academy of Sciences of the United States of America, vol. 109, no. 31, pp. E2110-E2116, 2012.

[10] K. Ohshima, K. Inoue, A. Fujiwara et al., "Let-7 microRNA family Is selectively secreted into the extracellular environment via exosomes in a metastatic gastric cancer cell line," PLOS ONE, vol. 5, no. 10, Article ID e13247, 2010.

[11] J. Lu, G. Getz, E. A. Miska et al., "MicroRNA expression profiles classify human cancers," Nature, vol. 435, no. 7043, pp. 834-838, 2005.

[12] S. Volinia, G. A. Calin, C.-G. Liu et al., "A microRNA expression signature of human solid tumors defines cancer gene targets," Proceedings of the National Academy of Sciences of the United States of America, vol. 103, no. 7, pp. 2257-2261, 2006.

[13] R. J. Webster, K. M. Giles, K. J. Price, P. M. Zhang, J. S. Mattick, and P. J. Leedman, "Regulation of epidermal growth factor receptor signaling in human cancer cells by microRNA-7," The Journal of Biological Chemistry, vol. 284, no. 9, pp. 5731-5741, 2009.

[14] M. W. Nasser, J. Datta, G. Nuovo et al., "Down-regulation of micro-RNA-1 (miR-1) in lung cancer: suppression of tumorigenic property of lung cancer cells and their sensitization to doxorubicin-induced apoptosis by miR-1," The Journal of Biological Chemistry, vol. 283, no. 48, pp. 33394-33405, 2008.

[15] M. Garofalo, C. Quintavalle, G. Di Leva et al., "MicroRNA signatures of TRAIL resistance in human non-small cell lung cancer," Oncogene, vol. 27, no. 27, pp. 3845-3855, 2008.

[16] Y. Hayashita, H. Osada, Y. Tatematsu et al., "A polycistronic MicroRNA cluster, $m i R-17-92$, is overexpressed in human lung cancers and enhances cell proliferation," Cancer Research, vol. 65, no. 21, pp. 9628-9632, 2005.

[17] Y. Fujita, F. Takeshita, K. Kuwano, and T. Ochiya, "RNAi therapeutic platforms for lung diseases," Pharmaceuticals, vol. 6, no. 2, pp. 223-250, 2013.

[18] S.-L. Yu, H.-Y. Chen, G.-C. Chang et al., "microRNA signature predicts survival and relapse in lung cancer," Cancer Cell, vol. 13, no. 1, pp. 48-57, 2008.

[19] M. Redova, J. Sana, and O. Slaby, "Circulating miRNAs as new blood-based biomarkers for solid cancers," Future Oncology, vol. 9, no. 3, pp. 387-402, 2013.

[20] K. Zen and C.-Y. Zhang, "Circulating microRNAs: a novel class of biomarkers to diagnose and monitor human cancers," Medicinal Research Reviews, vol. 32, no. 2, pp. 326-348, 2012.

[21] J. D. Arroyo, J. R. Chevillet, E. M. Kroh et al., "Argonaute2 complexes carry a population of circulating microRNAs independent of vesicles in human plasma," Proceedings of the National Academy of Sciences of the United States of America, vol. 108, no. 12, pp. 5003-5008, 2011. 
[22] Y. Fujita, Y. Yoshioka, S. Ito, J. Araya, K. Kuwano, and T. Ochiya, "Intercellular communication by extracellular vesicles and their microRNAs in Asthma," Clinical Therapeutics, vol. 36, no. 6, pp. 873-881, 2014.

[23] C. Théry, M. Ostrowski, and E. Segura, "Membrane vesicles as conveyors of immune responses," Nature Reviews Immunology, vol. 9, no. 8, pp. 581-593, 2009.

[24] G. Rabinowits, C. Gerçel-Taylor, J. M. Day, D. D. Taylor, and G. H. Kloecker, "Exosomal microRNA: a diagnostic marker for lung cancer," Clinical Lung Cancer, vol. 10, no. 1, pp. 42-46, 2009.

[25] D. J. Gibbings, C. Ciaudo, M. Erhardt, and O. Voinnet, "Multivesicular bodies associate with components of miRNA effector complexes and modulate miRNA activity," Nature Cell Biology, vol. 11, no. 9, pp. 1143-1149, 2009.

[26] C. Villarroya-Beltri, C. Gutiérrez-Vázquez, F. Sánchez-Cabo et al., "Sumoylated hnRNPA2B1 controls the sorting of miRNAs into exosomes through binding to specific motifs," Nature Communications, vol. 4, article 2980, 2013.

[27] D. Koppers-Lalic, M. Hackenberg, I. V. Bijnsdorp et al., "Nontemplated nucleotide additions distinguish the small RNA composition in cells from exosomes," Cell Reports, vol. 8, no. 6, pp. 1649-1658, 2014.

[28] N. Kosaka, H. Iguchi, K. Hagiwara, Y. Yoshioka, F. Takeshita, and T. Ochiya, "Neutral sphingomyelinase 2 (nSMase2)dependent exosomal transfer of angiogenic micrornas regulate cancer cell metastasis," The Journal of Biological Chemistry, vol. 288, no. 15, pp. 10849-10859, 2013.

[29] H. F. G. Heijnen, A. E. Schiel, R. Fijnheer, H. J. Geuze, and J. J. Sixma, "Activated platelets release two types of membrane vesicles: microvesicles by surface shedding and exosomes derived from exocytosis of multivesicular bodies and $\alpha$-granules," Blood, vol. 94, no. 11, pp. 3791-3799, 1999.

[30] M. Yanez-Mo, P. R. Siljander, Z. Andreu et al., "Biological properties of extracellular vesicles and their physiological functions," Journal of Extracellular Vesicles, vol. 4, Article ID 27066, 2015.

[31] H. C. Christianson, K. J. Svensson, T. H. Van Kuppevelt, J.P. Li, and M. Belting, "Cancer cell exosomes depend on cellsurface heparan sulfate proteoglycans for their internalization and functional activity," Proceedings of the National Academy of Sciences of the United States of America, vol. 110, no. 43, pp. 17380-17385, 2013.

[32] R. Cazzoli, F. Buttitta, M. Di Nicola et al., "microRNAs derived from circulating exosomes as noninvasive biomarkers for screening and diagnosing lung cancer," Journal of Thoracic Oncology, vol. 8, no. 9, pp. 1156-1162, 2013.

[33] J. Takamizawa, H. Konishi, K. Yanagisawa et al., "Reduced expression of the let-7 microRNAs in human lung cancers in association with shortened postoperative survival," Cancer Research, vol. 64, no. 11, pp. 3753-3756, 2004.

[34] S. M. Johnson, H. Grosshans, J. Shingara et al., "RAS is regulated by the let-7 microRNA family," Cell, vol. 120, no. 5, pp. 635-647, 2005.

[35] Y. S. Lee and A. Dutta, "The tumor suppressor microRNA let-7 represses the HMGA2 oncogene," Genes and Development, vol. 21, no. 9, pp. 1025-1030, 2007.

[36] B. Meyer, S. Loeschke, A. Schultze et al., "HMGA2 overexpression in non-small cell lung cancer," Molecular Carcinogenesis, vol. 46, no. 7, pp. 503-511, 2007.

[37] M. S. Kumar, J. Lu, K. L. Mercer, T. R. Golub, and T. Jacks, "Impaired microRNA processing enhances cellular transformation and tumorigenesis," Nature Genetics, vol. 39, no. 5, pp. 673677, 2007.
[38] E. Koscianska, V. Baev, K. Skreka, K. Oikonomaki, V. Rusinov, and K. Kalantidis, "Prediction and preliminary validation of oncogene regulation by miRNAs," BMC Molecular Biology, vol. 8, article 79, 2007.

[39] C. D. Johnson, A. Esquela-Kerscher, G. Stefani et al., “The let7 microRNA represses cell proliferation pathways in human cells," Cancer Research, vol. 67, no. 16, pp. 7713-7722, 2007.

[40] A. Ota, H. Tagawa, S. Karnan et al., "Identification and characterization of a novel gene, C13orf25, as a target for 13q31-q32 amplification in malignant lymphoma," Cancer Research, vol. 64, no. 9, pp. 3087-3095, 2004.

[41] M. R. Davidson, J. E. Larsen, I. A. Yang et al., "microRNA-218 is deleted and downregulated in lung squamous cell carcinoma," PLoS ONE, vol. 5, no. 9, Article ID e12560, 2010.

[42] M. E. Hatley, D. M. Patrick, M. R. Garcia et al., "Modulation of K-Ras-dependent lung tumorigenesis by MicroRNA-21," Cancer Cell, vol. 18, no. 3, pp. 282-293, 2010.

[43] A. Mogi and H. Kuwano, “TP53 mutations in nonsmall cell lung cancer," Journal of Biomedicine and Biotechnology, vol. 2011, Article ID 583929, 9 pages, 2011.

[44] L. He, X. He, L. P. Lim et al., "A microRNA component of the p53 tumour suppressor network," Nature, vol. 447, no. 7148, pp. 1130-1134, 2007.

[45] H. Hermeking, "The miR-34 family in cancer and apoptosis," Cell Death \& Differentiation, vol. 17, no. 2, pp. 193-199, 2010.

[46] M. Yamakuchi and C. J. Lowenstein, "MiR-34, SIRT1 and p53: the feedback loop," Cell Cycle, vol. 8, no. 5, pp. 712-715, 2009.

[47] A. L. Kasinski and F. J. Slack, "miRNA-34 prevents cancer initiation and progression in a therapeutically resistant $\mathrm{K}$ ras and p53-induced mouse model of lung adenocarcinoma," Cancer Research, vol. 72, no. 21, pp. 5576-5587, 2012.

[48] B. Liu, X.-C. Peng, X.-L. Zheng, J. Wang, and Y.-W. Qin, “miR126 restoration down-regulate VEGF and inhibit the growth of lung cancer cell lines in vitro and in vivo," Lung Cancer, vol. 66, no. 2, pp. 169-175, 2009.

[49] M. Crawford, E. Brawner, K. Batte et al., "MicroRNA-126 inhibits invasion in non-small cell lung carcinoma cell lines," Biochemical and Biophysical Research Communications, vol. 373, no. 4, pp. 607-612, 2008.

[50] S. M. Feller, "CrK family adaptors-signalling complex formation and biological roles," Oncogene, vol. 20, no. 44, pp. 6348-6371, 2001.

[51] Y. Kobashigawa, M. Sakai, M. Naito et al., "Structural basis for the transforming activity of human cancer-related signaling adaptor protein CRK," Nature Structural \& Molecular Biology, vol. 14, no. 6, pp. 503-510, 2007.

[52] D. L. Gibbons, W. Lin, C. J. Creighton et al., "Contextual extracellular cues promote tumor cell EMT and metastasis by regulating miR-200 family expression," Genes \& Development, vol. 23, no. 18, pp. 2140-2151, 2009.

[53] L. Jiang, Q. Huang, S. Zhang et al., "Hsa-miR-125a-3p and hsamiR-125a-5p are downregulated in non-small cell lung cancer and have inverse effects on invasion and migration of lung cancer cells," BMC Cancer, vol. 10, article 318, 2010.

[54] J.-G. Zhang, J.-J. Wang, F. Zhao, Q. Liu, K. Jiang, and G.H. Yang, "MicroRNA-21 (miR-21) represses tumor suppressor PTEN and promotes growth and invasion in non-small cell lung cancer (NSCLC)," Clinica Chimica Acta, vol. 411, no. 11-12, pp. 846-852, 2010.

[55] U. Savita and D. Karunagaran, "MicroRNA-106b-25 cluster targets $\beta$-TRCP2, increases the expression of Snail and enhances 
cell migration and invasion in H1299 (non small cell lung cancer) cells," Biochemical and Biophysical Research Communications, vol. 434, no. 4, pp. 841-847, 2013.

[56] N. M. White, C. R. Cabanski, J. M. Silva-Fisher, H. X. Dang, R. Govindan, and C. A. Maher, "Transcriptome sequencing reveals altered long intergenic non-coding RNAs in lung cancer," Genome Biology, vol. 15, no. 8, article 429, 2014.

[57] Y.-R. Yang, S.-Z. Zang, C.-L. Zhong, Y.-X. Li, S.-S. Zhao, and X.J. Feng, "Increased expression of the lncRNA PVT1 promotes tumorigenesis in non-small cell lung cancer," International Journal of Clinical and Experimental Pathology, vol. 7, no. 10, pp. 6929-6935, 2014.

[58] J. Silva, V. García, Á. Zaballos et al., "Vesicle-related microRNAs in plasma of nonsmall cell lung cancer patients and correlation with survival," European Respiratory Journal, vol. 37, no. 3, pp. 617-623, 2011.

[59] M. Rodríguez, J. Silva, A. López-Alfonso et al., "Different exosome cargo from plasma/bronchoalveolar lavage in nonsmall-cell lung cancer," Genes Chromosomes and Cancer, vol. 53, no. 9, pp. 713-724, 2014.

[60] L. Lu, X. Zhang, B. Zhang, X. Zhang, and J. Wu, "Synaptic acetylcholinesterase targeted by microRNA-212 functions as a tumor suppressor in non-small cell lung cancer," International Journal of Biochemistry and Cell Biology, vol. 45, no. 11, pp. 25302540, 2013.

[61] H. Ebi, T. Sato, N. Sugito et al., "Counterbalance between RB inactivation and miR-17-92 overexpression in reactive oxygen species and DNA damage induction in lung cancers," Oncogene, vol. 28, no. 38, pp. 3371-3379, 2009.

[62] M. Garofalo, G. Di Leva, G. Romano et al., "miR-221\&222 regulate TRAIL resistance and enhance tumorigenicity through PTEN and TIMP3 downregulation," Cancer Cell, vol. 16, no. 6, pp. 498-509, 2009.

[63] L. Du, J. J. Schageman, M. C. Subauste et al., "miR-93, miR98, and miR-197 regulate expression of tumor suppressor gene FUS1," Molecular Cancer Research, vol. 7, no. 8, pp. 1234-1243, 2009.

[64] H. Zhao, L. Zhu, Y. Jin, H. Ji, X. Yan, and X. Zhu, "miR375 is highly expressed and possibly transactivated by achaetescute complex homolog 1 in small-cell lung cancer cells," Acta Biochimica et Biophysica Sinica, vol. 44, no. 2, pp. 177-182, 2012.

[65] H. Matsubara, T. Takeuchi, E. Nishikawa et al., "Apoptosis induction by antisense oligonucleotides against miR-17-5p and miR-20a in lung cancers overexpressing miR-17-92," Oncogene, vol. 26, no. 41, pp. 6099-6105, 2007.

[66] S. Arora, A. R. Ranade, N. L. Tran et al., "microRNA-328 is associated with (non-small) cell lung cancer (NSCLC) brain metastasis and mediates NSCLC migration," International Journal of Cancer, vol. 129, no. 11, pp. 2621-2631, 2011.

[67] P.-Y. Wang, Y.-J. Li, S. Zhang et al., "Regulating A549 cells growth by ASO inhibiting miRNA expression," Molecular and Cellular Biochemistry, vol. 339, no. 1-2, pp. 163-171, 2010.

[68] S. Jiang, H.-W. Zhang, M.-H. Lu et al., "MicroRNA-155 functions as an OncomiR in breast cancer by targeting the suppressor of cytokine signaling 1 gene," Cancer Research, vol. 70, no. 8, pp. 3119-3127, 2010.

[69] Y. Yamanaka, H. Tagawa, N. Takahashi et al., "Aberrant overexpression of microRNAs activate AKT signaling via downregulation of tumor suppressors in natural killer-cell lymphoma/leukemia," Blood, vol. 114, no. 15, pp. 3265-3275, 2009.

[70] W. Kong, H. Yang, L. He et al., "MicroRNA-155 is regulated by the transforming growth factor $\beta /$ Smad pathway and contributes to epithelial cell plasticity by targeting RhoA," Molecular and Cellular Biology, vol. 28, no. 22, pp. 6773-6784, 2008.

[71] M. Zhan, Q. Qu, G. Wang et al., "Let-7c inhibits NSCLC cell proliferation by targeting HOXA1," Asian Pacific Journal of Cancer Prevention, vol. 14, no. 1, pp. 387-392, 2013.

[72] E. Miko, Z. Margitai, Z. Czimmerer et al., "MiR-126 inhibits proliferation of small cell lung cancer cells by targeting SLC7A5," FEBS Letters, vol. 585, no. 8, pp. 1191-1196, 2011.

[73] X. Dang, A. Ma, L. Yang et al., "MicroRNA-26a regulates tumorigenic properties of EZH2 in human lung carcinoma cells," Cancer Genetics, vol. 205, no. 3, pp. 113-123, 2012.

[74] S. Xiong, Y. Zheng, P. Jiang, R. Liu, X. Liu, and Y. Chu, "microRNA-7 inhibits the growth of human non-small cell lung cancer A549 cells through targeting BCL-2," International Journal of Biological Sciences, vol. 7, no. 6, pp. 805-814, 2011.

[75] H. Wang, M. Li, R. Zhang et al., "Effect of miR-335 upregulation on the apoptosis and invasion of lung cancer cell A549 and H1299," Tumor Biology, vol. 34, no. 5, pp. 3101-3109, 2013.

[76] W. C. S. Cho, A. S. C. Chow, and J. S. K. Au, "MiR-145 inhibits cell proliferation of human lung adenocarcinoma by targeting EGFR and NUDT1," RNA Biology, vol. 8, no. 1, pp. 125-131, 2011.

[77] Z. Chen, H. Zeng, Y. Guo et al., "miRNA-145 inhibits non-small cell lung cancer cell proliferation by targeting c-Myc," Journal of Experimental \& Clinical Cancer Research, vol. 29, article 151, 2010.

[78] R. Yin, S. Zhang, Y. Wu et al., "microRNA-145 suppresses lung adenocarcinoma-initiating cell proliferation by targeting OCT4," Oncology Reports, vol. 25, no. 6, pp. 1747-1754, 2011.

[79] N. Zhang, Y. Su, and L. Xu, "Targeting PKCe by miR-143 regulates cell apoptosis in lung cancer," FEBS Letters, vol. 587, no. 22, pp. 3661-3667, 2013.

[80] S. Feng, S. Cong, X. Zhang et al., "MicroRNA-192 targeting retinoblastoma 1 inhibits cell proliferation and induces cell apoptosis in lung cancer cells," Nucleic Acids Research, vol. 39, no. 15 , pp. 6669-6678, 2011.

[81] M. Lizé, A. Klimke, and M. Dobbelstein, "MicroRNA-449 in cell fate determination," Cell Cycle, vol. 10, no. 17, pp. 2874-2882, 2011.

[82] G. Mudduluru, P. Ceppi, R. Kumarswamy, G. V. Scagliotti, M. Papotti, and H. Allgayer, "Regulation of Axl receptor tyrosine kinase expression by miR-34a and miR-199a/b in solid cancer," Oncogene, vol. 30, no. 25, pp. 2888-2899, 2011.

[83] N. H. Kim, H. S. Kim, X.-Y. Li et al., "A p53/miRNA-34 axis regulates Snaill-dependent cancer cell epithelial-mesenchymal transition," The Journal of Cell Biology, vol. 195, no. 3, pp. 417433, 2011.

[84] X. Wang, C. Ling, Y. Bai, and J. Zhao, "MicroRNA-206 is associated with invasion and metastasis of lung cancer," Anatomical Record, vol. 294, no. 1, pp. 88-92, 2011.

[85] G. Chen, I. A. Umelo, S. Lv et al., "miR-146a inhibits cell growth, cell migration and induces apoptosis in non-small cell lung cancer cells," PLoS ONE, vol. 8, no. 3, Article ID e60317, 2013.

[86] C. Wang, X. Wang, H. Liang et al., "miR-203 inhibits cell proliferation and migration of lung cancer cells by targeting PKC $\alpha$," PLoS ONE, vol. 8, no. 9, Article ID e73985, 2013.

[87] P. A. Gregory, A. G. Bert, E. L. Paterson et al., "The miR200 family and miR-205 regulate epithelial to mesenchymal transition by targeting ZEB1 and SIP1," Nature Cell Biology, vol. 10, no. 5, pp. 593-601, 2008. 
[88] Y.-S. Wang, Y.-H. Wang, H.-P. Xia, S.-W. Zhou, G. SchmidBindert, and C.-C. Zhou, "MicroRNA-214 regulates the acquired resistance to gefitinib via the PTEN/AKT pathway in EGFR-mutant cell lines," Asian Pacific Journal of Cancer Prevention, vol. 13, no. 1, pp. 255-260, 2012.

[89] F.-Q. Nie, Q. Zhu, T.-P. Xu et al., "Long non-coding RNA MVIH indicates a poor prognosis for non-small cell lung cancer and promotes cell proliferation and invasion," Tumour Biology, vol. 35, no. 8, pp. 7587-7594, 2014.

[90] W. Chen, W. Böcker, J. Brosius, and H. Tiedge, "Expression of neural BC200 RNA in human tumours," Journal of Pathology, vol. 183, no. 3, pp. 345-351, 1997.

[91] L. Gao, A. Mai, X. Li et al., "LncRNA-DQ786227-mediated cell malignant transformation induced by benzo(a)pyrene," Toxicology Letters, vol. 223, no. 2, pp. 205-210, 2013.

[92] L. H. Schmidt, T. Spieker, S. Koschmieder et al., "The long noncoding MALAT-1 RNA indicates a poor prognosis in nonsmall cell lung cancer and induces migration and tumor growth," Journal of Thoracic Oncology, vol. 6, no. 12, pp. 19841992, 2011.

[93] Y. Yang, H. Li, S. Hou, B. Hu, J. Liu, and J. Wang, "The noncoding RNA expression profile and the effect of lncRNA AK126698 on cisplatin resistance in non-small-cell lung cancer cell," PLoS ONE, vol. 8, no. 5, Article ID e65309, 2013.

[94] P. Thai, S. Statt, C. H. Chen, E. Liang, C. Campbell, and R. $\mathrm{Wu}$, "Characterization of a novel long noncoding RNA, SCAL1, induced by cigarette smoke and elevated in lung cancer cell lines," The American Journal of Respiratory Cell and Molecular Biology, vol. 49, no. 2, pp. 204-211, 2013.

[95] Y. Zhuang, X. Wang, H. T. Nguyen et al., "Induction of long intergenic non-coding RNA HOTAIR in lung cancer cells by type I collagen," Journal of Hematology and Oncology, vol. 6, no. 1, article 35, 2013.

[96] Z. Liu, M. Sun, K. Lu et al., “The long noncoding RNA HOTAIR contributes to cisplatin resistance of human lung adenocarcinoma cells via downregualtion of $\mathrm{p} 21^{W A F 1 / C I P 1}$ expression," PLoS ONE, vol. 8, no. 10, Article ID e77293, 2013.

[97] H. Ono, N. Motoi, H. Nagano et al., "Long noncoding RNA HOTAIR is relevant to cellular proliferation, invasiveness, and clinical relapse in small-cell lung cancer," Cancer Medicine, vol. 3, no. 3, pp. 632-642, 2014.

[98] M. Sun, X.-H. Liu, K.-M. Wang et al., "Downregulation of BRAF activated non-coding RNA is associated with poor prognosis for non-small cell lung cancer and promotes metastasis by affecting epithelial-mesenchymal transition," Molecular Cancer, vol. 13, no. 1, article 68, 2014.

[99] K.-H. Lu, W. Li, X.-H. Liu et al., "Long non-coding RNA MEG3 inhibits NSCLC cells proliferation and induces apoptosis by affecting p53 expression," BMC Cancer, vol. 13, article 461, 2013.

[100] M. Sun, X.-H. Liu, K.-H. Lu et al., "EZH2-mediated epigenetic suppression of long noncoding RNA SPRY4-IT1 promotes NSCLC cell proliferation and metastasis by affecting the epithelial-mesenchymal transition," Cell Death and Disease, vol. 5, no. 6, Article ID e1298, 2014.

[101] E.-B. Zhang, D.-D. Yin, M. Sun et al., "P53-regulated long noncoding RNA TUG1 affects cell proliferation in human nonsmall cell lung cancer, partly through epigenetically regulating HOXB7 expression," Cell Death \& Disease, vol. 5, Article ID e1243, 2014.

[102] S. Roush and F. J. Slack, "The let-7 family of microRNAs," Trends in Cell Biology, vol. 18, no. 10, pp. 505-516, 2008.
[103] P. Leidinger, A. Keller, and E. Meese, "Micrornas-important molecules in lung cancer research," Frontiers in Genetics, vol. 2, article 104, 2012.

[104] L. J. Chin, E. Ratner, S. Leng et al., "A SNP in a let-7 microRNA complementary site in the KRAS $3^{\prime}$ untranslated region increases non-small cell lung cancer risk," Cancer Research, vol. 68, no. 20, pp. 8535-8540, 2008.

[105] X. He, C. Duan, J. Chen et al., "Let-7a elevates p21WAF1 levels by targeting of NIRF and suppresses the growth of A549 lung cancer cells," FEBS Letters, vol. 583, no. 21, pp. 3501-3507, 2009.

[106] M. Unoki, T. Nishidate, and Y. Nakamura, "ICBP90, an E2F-1 target, recruits $\mathrm{HDACl}$ and binds to methyl-CpG through its SRA domain," Oncogene, vol. 23, no. 46, pp. 7601-7610, 2004.

[107] B. Zhao, H. Han, J. Chen et al., "microRNA let-7c inhibits migration and invasion of human non-small cell lung cancer by targeting ITGB3 and MAP4K3," Cancer Letters, vol. 342, no. 1, pp. 43-51, 2014.

[108] W. Gao, Y. Yu, H. Cao et al., "Deregulated expression of miR21, miR-143 and miR-181a in non small cell lung cancer is related to clinicopathologic characteristics or patient prognosis," Biomedicine and Pharmacotherapy, vol. 64, no. 6, pp. 399408, 2010.

[109] M. Seike, A. Goto, T. Okano et al., "MiR-21 is an EGFR-regulated anti-apoptotic factor in lung cancer in never-smokers," Proceedings of the National Academy of Sciences of the United States of America, vol. 106, no. 29, pp. 12085-12090, 2009.

[110] D. Frezzetti, M. De Menna, P. Zoppoli et al., "Upregulation of miR-21 by Ras in vivo and its role in tumor growth," Oncogene, vol. 30, no. 3, pp. 275-286, 2011.

[111] X. Pan, Z.-X. Wang, and R. Wang, "MicroRNA-21: a novel therapeutic target in human cancer," Cancer Biology and Therapy, vol. 10, no. 12, pp. 1224-1232, 2010.

[112] M. Chiba, M. Kimura, and S. Asari, "Exosomes secreted from human colorectal cancer cell lines contain mRNAs, microRNAs and natural antisense RNAs, that can transfer into the human hepatoma HepG2 and lung cancer A549 cell lines," Oncology Reports, vol. 28, no. 5, pp. 1551-1558, 2012.

[113] Y. Sun, Y. Bai, F. Zhang, Y. Wang, Y. Guo, and L. Guo, "miR126 inhibits non-small cell lung cancer cells proliferation by targeting EGFL7," Biochemical and Biophysical Research Communications, vol. 391, no. 3, pp. 1483-1489, 2010.

[114] G. Ren and Y. Kang, "A one-two punch of miR-126/126* against metastasis," Nature Cell Biology, vol. 15, no. 3, pp. 231-233, 2013. 

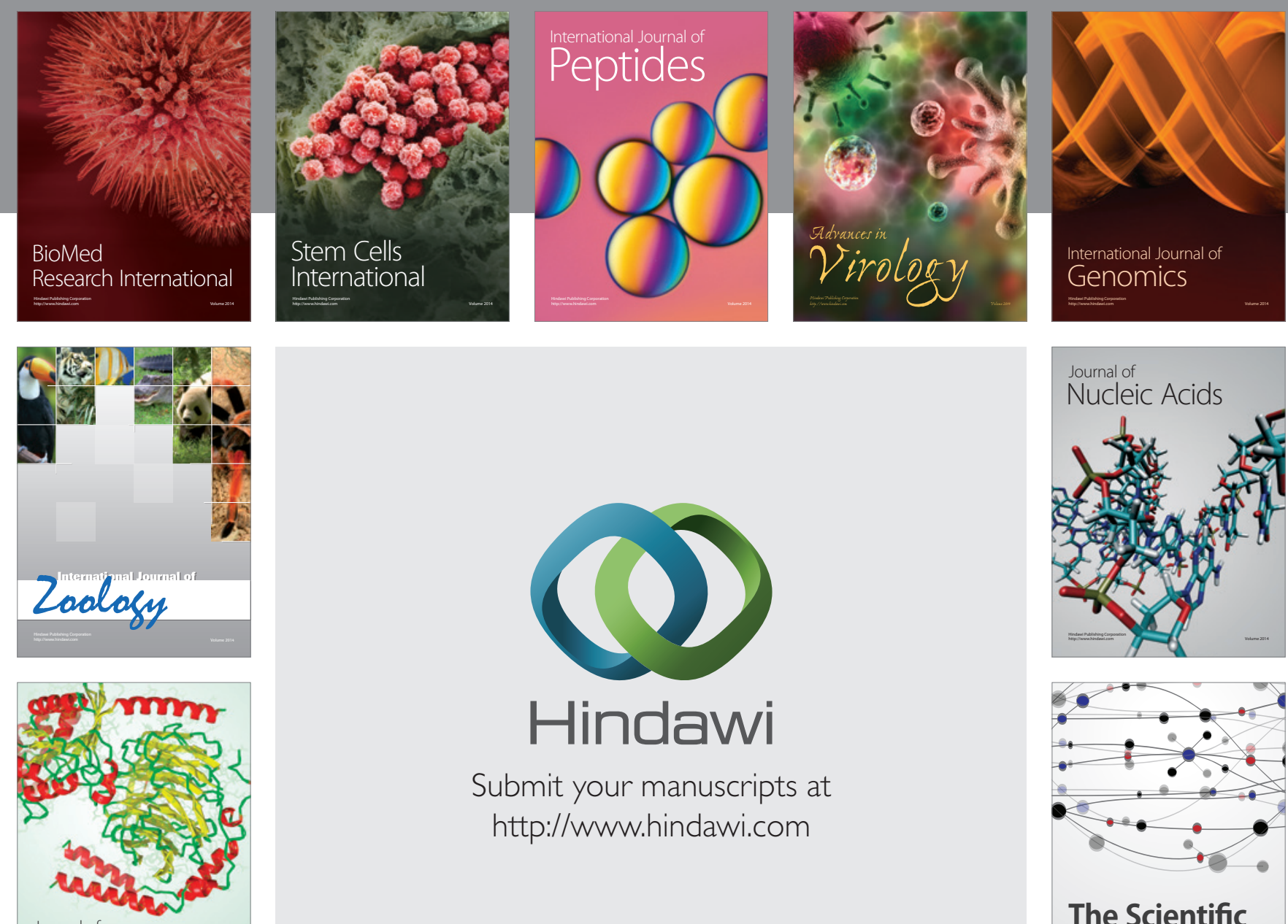

Submit your manuscripts at

http://www.hindawi.com

Journal of
Signal Transduction
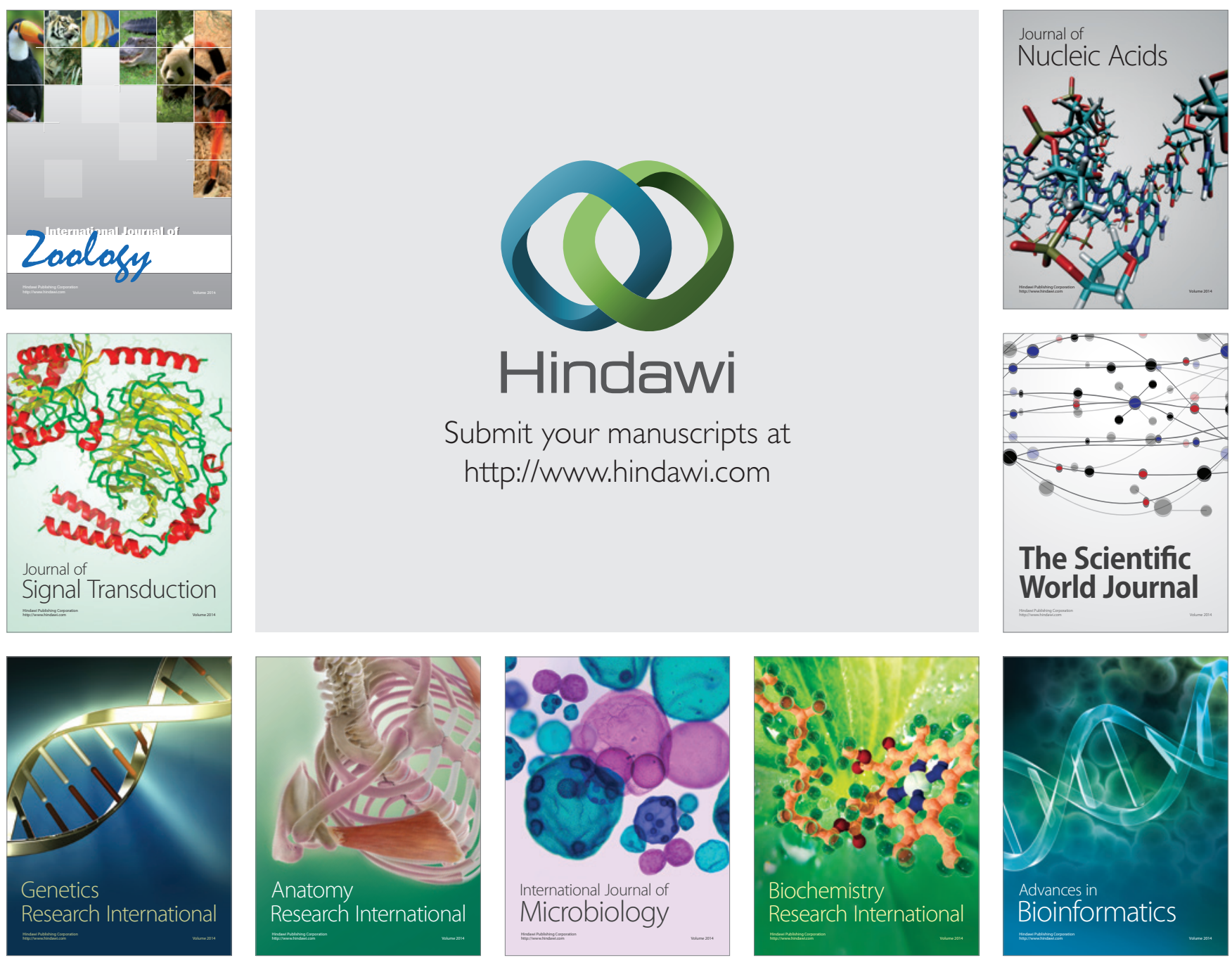

The Scientific World Journal
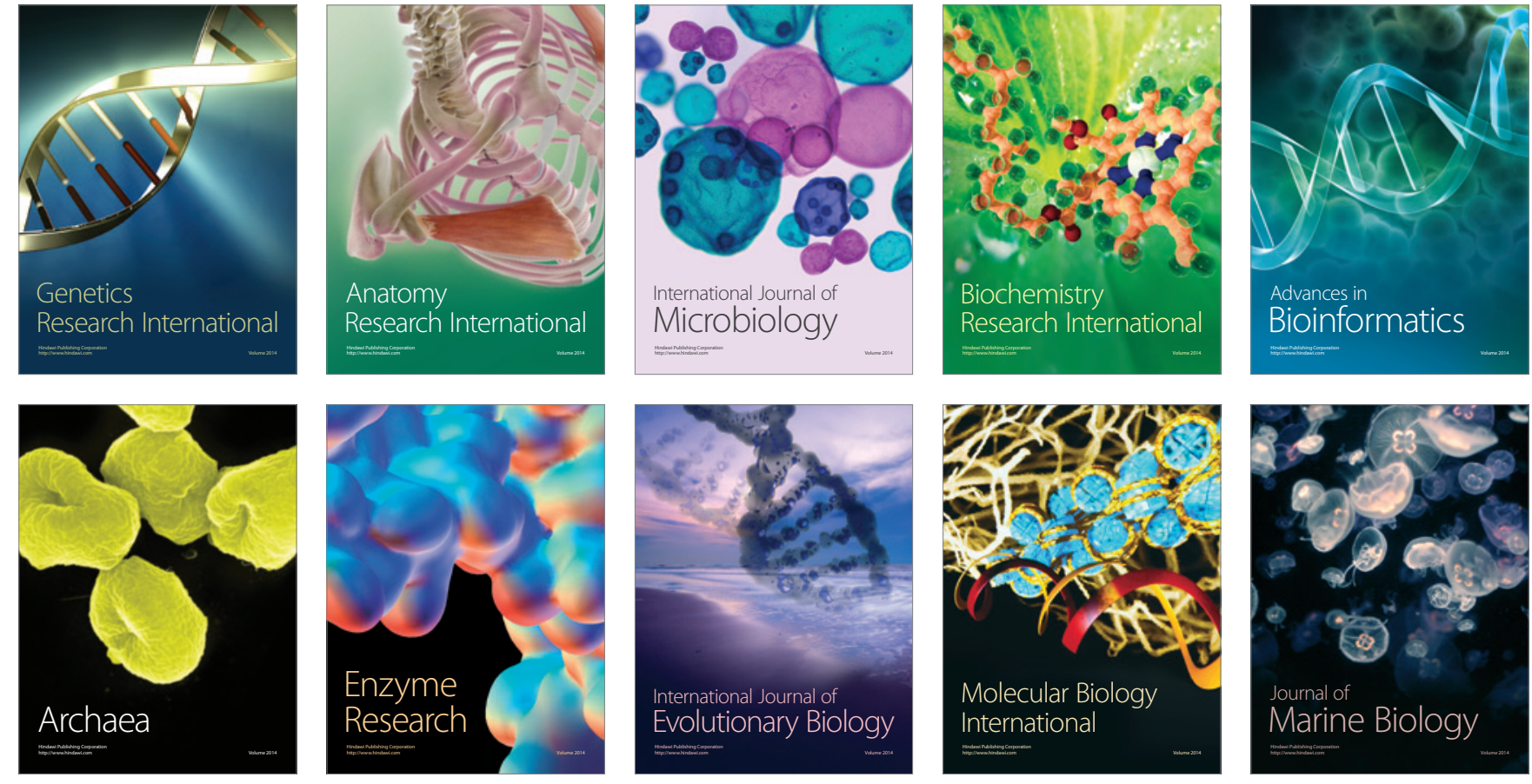